\title{
Robert McBride, Molière et son premier Tartuffe: genèse et évolution d'une pièce à scandale
}

\section{Monica Pavesio}

\section{(2) OpenEdition}

\section{Journals}

\section{Edizione digitale}

URL: http://journals.openedition.org/studifrancesi/9194

DOI: $10.4000 /$ studifrancesi.9194

ISSN: 2421-5856

\section{Editore}

Rosenberg \& Sellier

\section{Edizione cartacea}

Data di pubblicazione: 1 juin 2008

Paginazione: 180-181

ISSN: 0039-2944

\section{Notizia bibliografica digitale}

Monica Pavesio, «Robert McBride, Molière et son premier Tartuffe: genèse et évolution d'une pièce à scandale», Studi Francesi [Online], 154 (LII | I) | 2008, online dal 30 novembre 2015, consultato il 11 janvier 2021. URL: http://journals.openedition.org/studifrancesi/9194 ; DOI: https://doi.org/10.4000/ studifrancesi.9194

Questo documento è stato generato automaticamente il 11 janvier 2021.

\section{(c) $(1)$}

Studi Francesi è distribuita con Licenza Creative Commons Attribuzione - Non commerciale - Non opere derivate 4.0 Internazionale. 


\title{
Robert McBride, Molière et son premier Tartuffe: genèse et évolution d'une pièce à scandale
}

\author{
Monica Pavesio
}

\section{NOTIZIA}

ROBERT MCBRIDE, Molière et son premier Tartuffe: genèse et évolution d'une pièce à scandale, Durham, University of Durham, 2005, pp. 270.

1 L'interessante libro di R. McBride ricostruisce le tre versioni del Tartuffe di Molière, composte fra il 1664 ed il 1669, nonché le circostanze storiche, religiose e politiche che ne hanno determinato i cambiamenti. La pièce più controversa e misteriosa di Molière è stata in effetti talmente rimaneggiata dal suo stesso autore nel quinquennio 1664-1669, che la terza versione rappresentata il 5 febbraio 1669 è del tutto differente dalla versione originale, oggi perduta, messa in scena il 12 maggio 1664 a Versailles.

2 McBride ricostruisce 'l'affaire du Tartuffe', interrogandosi sulla natura e sul contenuto del primo Tartuffe, grazie a documenti dell'epoca ed alla collazione con la seconda versione del 1667, intitolata L'imposteur, e con la terza del 1669. Propone inoltre un affascinante affresco della corte di Luigi XIV, illustrando gli avvenimenti che determinarono la condanna del primo Tartuffe e resero necessarie le successive revisioni.

Grazie ad alcune interessanti scoperte sulla seconda versione della pièce, L'imposteur del 1667, e grazie alla comparazione effettuata dallo stesso McBride fra questa versione e la successiva del 1669, sono emerse numerose differenze fra le due opere. Queste differenze, collegando la versione del 1667 al primo Tartuffe, permettono di ricostruire, a grandi linee, la forma originale della prima versione e di comprendere meglio le critiche che ne originarono l'interdizione. 
4 Una bibliografia succinta, ma essenziale, diverse illustrazioni raffiguranti i personaggi che parteciparono alla cabale dei devoti concludono un volume che ha il pregio di riportare l'attenzione sulla travagliata genesi del Tartuffe, proponendo nuove e convincenti ricostruzioni della versione originale della pièce. 